\title{
Fiber Orientation Mechanism of Continuous Fiber Reinforced Thermoplastics Hybrid Parts Joined with Metallic Pins
}

\author{
Julian Popp ${ }^{1}$ (D) Tobias Kleffel ${ }^{1}$ - David Römisch ${ }^{2}$. Thomas Papke ${ }^{2}$ - Marion Merklein ${ }^{2}$. \\ Dietmar Drummer ${ }^{1}$
}

Received: 23 October 2020 / Accepted: 15 March 2021 / Published online: 17 April 2021

(c) The Author(s) 2021

\begin{abstract}
Continuous Fiber Reinforced Thermoplastic (CFRT) hybrid parts offer interesting possibilities for lightweight application, which can exceed the capabilities of mono material metal or CFRT parts. In this case, the joining technology oftentimes is the limiting factor. This study investigates a joining operation with metal pin structures which are additively manufactured via powder bed fusion featuring different diameters and tip geometries, which are inserted into the locally infrared heated CFRT part. The resulting fiber rearrangement is assessed using transmitted light microscopy, confocal laser scanning microscopy as well as micro-computer-tomography. It could be shown that for all assessed pin variants a similar distinct fiber displacement can be seen and that the pin diameter has a significant effect on the resulting fiber orientation with smaller pin diameters being advantageous because of gentle fiber displacement and reduced undulation. The tip geometry has only minor effect on the fiber orientation. Especially in the X/Y plane no systematic influence of the tip geometry on the fiber displacement could be observed. Based on the gained insights a three-stage model of the fiber orientation processes is proposed.
\end{abstract}

Keywords Organo sheet - Continuous fiber reinforced thermoplastics $\cdot$ Hybrid part $\cdot$ Pin · Fiber orientation $\cdot$ Joining

\section{Introduction}

Continuous fiber reinforced thermoplastics (CFRT) offer a high potential for lightweight construction due to their good stiffness and strength to weight ratio compared to classic engineering materials which makes them suitable for a wide range of applications in, for example, the automotive or aerospace industry [1]. Although above a certain fiber length of approximately $1.0 \mathrm{~mm}$ an increase of fiber length often does not lead to an increase

Julian Popp

julian.georg.popp@fau.de

1 Institute of Polymer Technology, Friedrich-Alexander-Universität Erlangen-Nürnberg, Erlangen, Germany

2 Institute of Manufacturing Technology, Friedrich-Alexander-Universität Erlangen-Nürnberg, Erlangen, Germany 
in stiffness in the direction of fiber orientation [2], CFRTs have significant advantages over short and long fiber reinforced thermoplastics: Among others, fiber orientations are easier to determine in the design process of the part and longer fiber lengths typically lead to superior properties in means of impact behavior [3] and strength [4] as shown on the example of glass fiber and polypropylene composite. Despite these advantages, there are applications where parts manufactured from CFRTs reach their limits, such as environments above the glass transition temperature (amorphous matrix material), respectively the melting temperature (semi crystalline matrix material) of the matrix or applications with high erosive wear [5]. An approach to address these challenges in lightweight design is the use of hybrid parts, which combine a CFRT component with a metallic lightweight component such as higher strength aluminum or steel alloys. Despite the high potential of this approach, it requires a reliable and yet cost efficient joining technology to be applicable in serial production.

For this approach, the joining operation represents the key technology, which has to address a wide range of challenges due to the dissimilar mechanical, physical, and chemical properties, such as differences in stiffness, thermal expansion and chemical incompatibilities [6]. This results in established joining technologies like welding [7] and gluing [8] reaching their limits [9] or not being suitable for the manufacturing of CFRT-metal hybrid parts. Furthermore, gluing typically leads to increased weight due to the adhesive itself and complicates recycling processes due to the bonding of different materials.

In the current state of the art fiber composite-metal hybrid part manufacturing, riveted and bolted joints are widely used. These methods typically create a force and/or form-fitting joint and are suitable to create durable composite-metal joints. However, bolted and riveted joints show some disadvantages such as the need to prepare precise bolt holes [10] as well as added weight due to the bolts and rivets themselves [7].

A joining method with potential to create hybrid parts consisting of a metal and an endless fiber reinforced polymer component is the use of metallic pin structures, which are inserted into the polymer component to create a form- and force-fitting joint. A number of studies investigate the use of, mostly additively manufactured, metal pins to create hybrid joints with continuous fiber reinforced thermosets (CFRP) where the pins are inserted into the polymer component before the curing process of the resin. For double-lap-shear joints with pin structures in comparison to adhesively joined reference samples without a pin structure, an increase of the maximum strength of $630 \%$ [11] and of the energy absorption before failure of $3000 \%$ [12] could be shown. In [13] Kolesnikov et al. compare different joining technologies, such as conventional and titan reinforced bolt joints with pin based joints to create CFRP-CFRP samples. In this study, the pin based joint showed the highest weight specific strength what can be taken as an indication for the high potential of pin based joints for light weight construction.

In [14] different pin-based through the thickness reinforced joints are compared by Sarantinos et al. In this study it is concluded that thin and long pins are favorable for a high energy response and that a form fit geometry typically leads to a high stiffness and strength response. However, only thermoset plastics which are joined with the pin structures before curing are investigated in this study, therefore, the results are only partially comparable to the joining of metal and CFRT components, since the joining process technology with uncured thermosetting matrix does significantly vary from joining of thermoplastic and different fiber orientation mechanisms can expected with different matrix systems due to different matrix properties. The influence of the pin geometry on the joint is investigated in [12] where two different pin geometries are tested and the resulting mechanical properties 
are compared. In [15] Sarantinos et al. show an optimization process of the pin geometry in metal-FRT joining using an automated optimization approach and experimental as well as numerical testing of the optimized geometries. Despite giving extensive insights into the design of optimized pin geometries for FRP, differences in the resulting fiber orientations have not been analyzed.

Eberl et al. investigates FRP-metals joints with a thermosetting matrix and carbon fibers with metallic pins. In this work, special focus lies on the effect of the fiber undulation on the load bearing capacity under quasi-static tensile loading. It was found that an increase of ultimate joint strength of up to $31.8 \%$ could be achieved with pins in formed holes in comparison to pins which are inserted into subsequently drilled holes which cause the destruction of load bearing fibers. It could be concluded that the fiber undulation caused by inserted pins is favorable in comparison to the destruction of fibers [16].

There are studies, which examine the general fiber displacement and resulting material structure. Hufenbach et al. investigate a similar joining technique, called "Thermoactivated Pinning" in which inductively heated metal pins are pushed through two CFRT samples to form a joint between both parts [17]. In contrast to most of the other cited studies, the pin exits the CFRT part on the bottom side. Hufenbach et al. discovered characteristic fiber rich and matrix rich areas within the molten zone, which resulted out of the fiber displacement [17]. Furthermore, some matrix is pressed out of the CFRT because of the insertion process, resulting in additional fiber distortion in the direction of the insertion motion, as fibers are dragged with the matrix flow.

In another study of Hufenbach et al., the use of molded instead of drilled bolt holes is investigated where the advantage of molded holes lies in the fact that fibers are not cut during the drilling process but are displaced to accommodate the bolt hole, which is a similar finding to the work of Eberl et al. [16]. In this study, the hole is created with a tapered pin, which is pushed through the heated twill woven glass-fiber reinforced polypropylene composite, and following the part is reconsolidated with a ring shaped plunger. The moulding process leads to a characteristic fiber displacement with quasi unidirectionally reinforced matrix rich zones and zones with significantly increased fiber content [18].

For CFRT-metal hybrid parts, the direct pressing of metallic pins into a locally heated CFRT part, to form a force-fitting as well as interlocking connection, is shown in Plettke et al. on the example of additively manufactured metallic pins [19] as well as in Kraus et al. on the example of cold formed metallic pins [20]. In the cited studies, the general feasibility to create a loadable metal-CFRT joint with this technique is demonstrated. In both studies, no systematical investigation of the influence of different pin geometries on the resulting fiber orientation is conducted. However, Kraus et al. showed the resulting fiber orientation on the example of a cylindrical pin with a diameter of $1.32 \mathrm{~mm}$ [20].

In [21] Meyer et al. describe a technology to join a (thermosetting or alternatively thermoplastic) fiber reinforced laminate with a second component via pin structures, which are manufactured on the second component. The design of the pin structures is described in detail. Especially a tapered tip is described as beneficial in means of gentle pin-insertion and improved fiber displacement.

Against this background, this study aims at creating an understanding of the fiber orientation processes which take place in the direct pin pressing. The pin structures used in this study are produced with powder bed fusion using a laser beam (PBF-LB [22]). The freedom of design offered by additive manufacturing allows for easy variation of the pin and pin-head geometry to study the effect of different diameters and head geometries on the fiber rearrangement. Furthermore, the PBF-LB allows the different geometries to be built up directly on a sheet metal. The final sample geometry, consisting of pin structure and sheet metal, is cut out subsequent to the additive manufacturing process using a laser 
cutting process. In conventional machining processes typical roughness values Ra for turning are between $0.4 \mu \mathrm{m}-6.3 \mu \mathrm{m}$ and for milling Ra values between $0.8 \mu \mathrm{m}-6.3 \mu \mathrm{m}$ can be achieved [23]. In contrast, the additive manufacturing process results in higher roughness values, depending on the inclination angle, due to the layer-by-layer production and the resulting staircase effect. The roughness values can be influenced by selecting suitable process parameters and powder properties.

When investigating the influence of different process parameters on the microstructure and physical properties of additive-manufactured 316L, Cherry et al. [25] found out that the volume energy density has a great influence on the surface roughness. It could be shown that the roughness values of the examined samples decrease with increasing volume energy density up to an optimum. A further increase of the volume energy density has a negative effect on the surface roughness. In [25] the highest surface roughness of approx. $\mathrm{Ra}=16 \mu \mathrm{m}$ was measured for specimens with a volume energy density of $\mathrm{Ev}=69.6 \mathrm{~J} / \mathrm{mm}^{3}$ and the lowest surface roughness of approx. $\mathrm{Ra}=8.5 \mu \mathrm{m}$ was measured at $\mathrm{Ev}=125.4 \mathrm{~J} / \mathrm{mm}^{3}$. Another process-related effect that affects the surface roughness is the adhesion of partially melted powder particles from the surrounding powder bed to the surface. The results of Strano et al. [26] regarding the investigation of the surface roughness of $316 \mathrm{~L}$ show that even with vertical surfaces with an inclination angle of $90^{\circ}$, although there are no stair steps present, powder particles adhere to the surface, which leads to a higher surface roughness.

The focus of this study is to systematically investigate the fiber displacement mechanisms and the influence of different pin diameters and tip geometries using transmitted light microscopy as well as $\mu$ m computer tomography and confocal laser scanning microscopy. The gained knowledge is supposed to allow for an optimization of the pin geometry design, aiming at gentle fiber displacement with minimized fiber damage which according to [27], can result in higher joint strengths.

\section{Material and Methods}

\subsection{GF-PP Samples}

For all tests, the CFRT component is a glass fiber reinforced polypropylene composite with an area of $400 \mathrm{~mm} \times 400 \mathrm{~mm}$, which is manufactured out of multiple layers of unidirectionally reinforced thermoplastic tapes stacked together and consolidated under the influence of heat and pressure. As unidirectionally reinforced thermoplastic tape, UDMAXTM GPP45-70 (Saudi Basic Industries Corporation, Riad, Saudi Arabia) with a nominal glass fiber content of 45 vol.- $\%$ respectively $70 \mathrm{wt} .-\%$ and natural color [28] is used. The number of stacked layers is 10 which results in a thickness of the CFRT component of $2 \mathrm{~mm}$ with a glass fiber content of $71.3 \mathrm{wt} .-\%$ (measured with a thermogravimetric analyzer TGA 5500 (TA Instruments, Newcastle, USA)). The manufactured CFRT components are then cut into samples with the size of $40 \mathrm{~mm} \times 20 \mathrm{~mm}$ using a water-cooled saw in order to avoid thermal damage of the samples.

The melting peak of the matrix material has been measured in a differential scanning calorimetry (DSC) analysis to $163.4^{\circ} \mathrm{C}$ (heating rate of $0.333 \mathrm{Ks}^{-1}$ ) and the melting process completion to $180^{\circ} \mathrm{C}$ using a Discovery DSC 2500 (TA Instruments, Newcastle, United States). 


\subsection{Definition of Pin-geometry}

In Plettke et al. pins with a diameter of $1.0 \mathrm{~mm}$ [19] and in Kraus et al. pins with a diameter of $1.32 \mathrm{~mm}$ [20] have been used to join metal and CFRT. In both studies loadable joints were created. Thus, the size of pin diameters chosen in the present study is similar. Consequently, three different pin diameters and four different tip geometries are defined resulting in 12 different pin types in order to investigate the influence of different pin diameter and tip geometry on the resulting fiber displacement (see Fig. 1). All investigated pin geometries have a height of $1.8 \mathrm{~mm}$. This height is chosen to examine pins with a high load bearing capacity due to deep insertion into the CFRT sample while not completely penetrating the sample. Furthermore, a certain compaction of the fibers under the inserted is expected, especially when using flat pins with tip angle of $180^{\circ}$. The $0.2 \mathrm{~mm}$ difference between pin height and sample thickness is expected to accommodate the compacted fibers. In comparison to Kraus et al., where the pins have an average height of $1.47 \mathrm{~mm}$ the pins in this study are $0.33 \mathrm{~mm}$ longer. [20]. The examined diameters $d$ are $1.00 \mathrm{~mm}, 1.25 \mathrm{~mm}$ and $1.50 \mathrm{~mm}$ and the tip angles $\alpha$ are $180^{\circ}$ (flat), $120^{\circ}, 90^{\circ}$ and $60^{\circ}$.

\subsection{Pin Manufacturing by PBF-LB}

The manufacturing of pin structures on sheet metals is realized by Powder Bed Fusion with a laser beam. As sheet metal and powder material, 316L (1.4404) is used with an initial sheet thickness of $t_{0}=1.5 \mathrm{~mm}$. The powder is manufactured by LPW Technology Ltd. with a powder size distribution from $d_{10}=19 \mu \mathrm{m}$ to $d_{90}=43 \mu \mathrm{m}$. In order to fix the sheet metal on the building platform and to prevent it from warping during the layer-by-layer manufacturing process, the $316 \mathrm{~L}$ sheet is clamped with 14 screws to the build platform. The thickness of each powder layer is set to $50 \mu \mathrm{m}$. The machine used for pin production was a Lasertec 30 SLM (DMG Mori, Bielefeld, Germany) equipped with a $600 \mathrm{~W}$ fiber laser and a building platform with a maximum size of $300 \times 300 \mathrm{~mm}^{2}$. To reduce residual stresses due to the heat impact during the process, the temperature of the build platform is set to $200^{\circ} \mathrm{C}$. The laser beam is shaped to a Gaussian profile with a focal spot size of
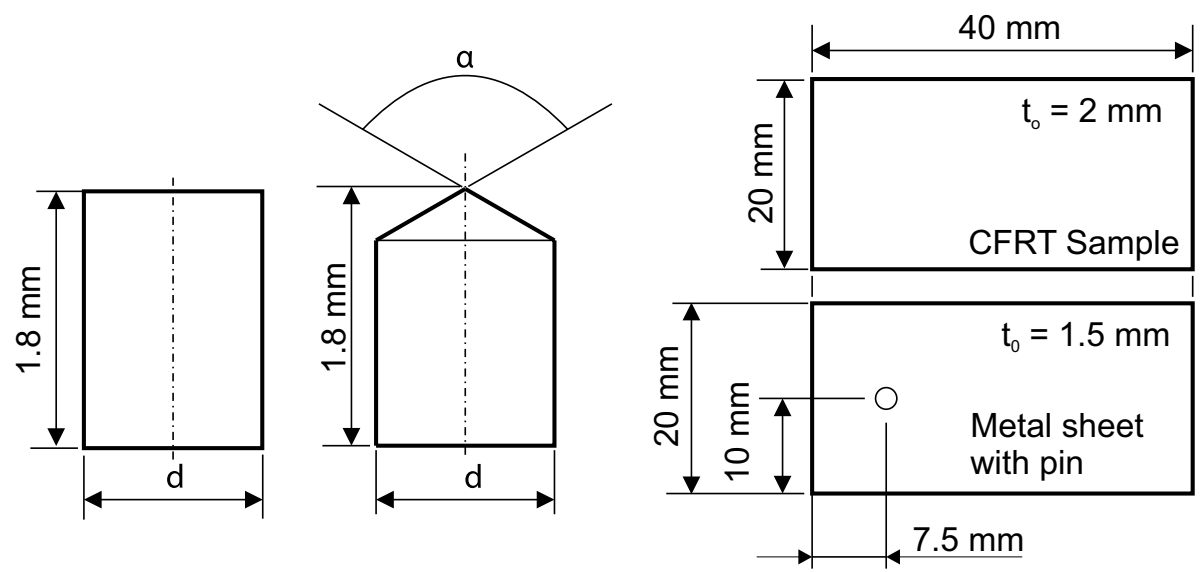

Fig. 1 Illustration of cylindrical (left) and cone-tipped pins (middle) and CFRT sample (right top) and metal sheet with pin (right bottom) 
approximately $70 \mu \mathrm{m}$ representing the minimum spot size of the machine. For the manufacturing of the pin structures the parameters for hatching the core structures were as follows: Layer thickness $1_{z}=50 \mu \mathrm{m}$, scanning speed $\mathrm{v}_{\mathrm{s}}=1000 \mathrm{~mm} / \mathrm{s}$, laser power $\mathrm{P}_{\mathrm{L}}=254 \mathrm{~W}$, hatch distance $h_{s}=0.1 \mathrm{~mm}$. This leads to a volume energy density of Ev $=51 \mathrm{~J} / \mathrm{mm}^{3}$. The volume energy is calculated according to [29] as follows:

$$
E_{v}=\frac{P_{L}}{v_{s} \cdot h_{s} \cdot l_{z}}
$$

With regard to surface roughness, the shell of the pin structures was created with a different parameter set. The laser power was reduced to $140 \mathrm{~W}$ and the scanning speed to $300 \mathrm{~mm} / \mathrm{s}$ to reduce surface roughness values. Since the shell is generated with a single track, formula (1) must be adjusted and the hatch distance needs to be replaced by the laser spot size according to Ciurana et al. [30]. This results in a volume energy density of $133 \mathrm{~J} /$ $\mathrm{mm}^{3}$ for the shell. After additive manufacturing, the samples, which consist of sheet metal and pin structure with a size of $20 \mathrm{~mm}$ by $40 \mathrm{~mm}$, are separated from the sheet metal by laser cutting with a TruLaser Cell 7020 (Trumpf, Ditzingen, Germany).

\subsection{D Laser Scanning Microscopy}

The surface of the manufactured pins is measured using a 3-D laser scanning confocal microscope VK-X1000 (Keyence Corporation, Osaka, Japan) to create 3D images of the pins and the corresponding analyzing software MultiFileAnalyzer (version 2.1.3.89, Keyence Corporation, Osaka, Japan) for the following post processing and measurements. For each pin, the arithmetical mean height of the surface $\mathrm{Ra}$ and the mean roughness depth $\mathrm{Rz}$ of the cylinder jacket is measured individually. Since the geometries vary significantly, the possible length of the measured sections varies between the different geometries with $400 \mu \mathrm{m}$ being the shortest possible length for pins with $1.5 \mathrm{~mm}$ in diameter and a $60^{\circ}$ tip angle. In order to ensure comparable results between the different geometries, all measurements are taken with a length of $400 \mu \mathrm{m}$. A high pass filter with a cut off wavelength $\lambda c$ of $0.8 \mathrm{~mm}$ is applied to remove long wavelength geometrical deviations. To minimize the impact of irregularities on the measurement results, five individual sections of measurement with an interval of 10 pixels, respectively $13.8 \mu \mathrm{m}$ between each section are taken for every pin and the average value of these measurements is calculated to obtain the final measured $\mathrm{Ra}$ and $\mathrm{Rz}$ values for each pin. Figure 2 shows an example of a measurement of the surface roughness on the cylinder jacket (left side). All measurements are taken on the lower third of the pin as shown in Fig. 2, as this is the only cylindrical area which is comparable over all investigated pin types due to tapered tips of some pin types. This procedure

Fig. 2 Illustration of Ra roughness sections of measuremen (red) on cylinder jacket in $\mathrm{z} / \mathrm{y}$ plane (left) and image in $\mathrm{x} / \mathrm{y}$ plane used to measure the actual diameter of the pin with a diameter of $1.25 \mathrm{~mm}$ (right)

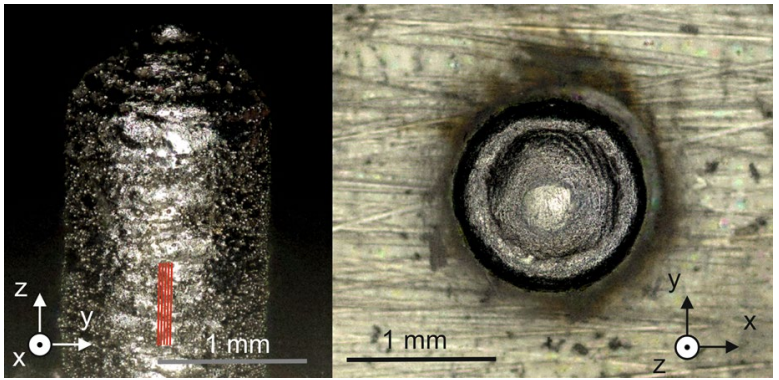


deviates from DIN-EN ISO 4288 [31]. Consequently, the measured values are only partially comparable with values obtained according to the norm.

In order to assess the dimensional accuracy of the manufactured pins, the pin height is measured with images taken in the Z/Y plane (left side in Fig. 2) and the diameter is measured with images taken in the $\mathrm{X} / \mathrm{Y}$ plane (right side in Fig. 2).

In addition to the pin structures, several 3D images of CFRT samples with different joining pressures are created as a means to assess the resulting topography of the CFRT sample (compare Sect. 2.5).

\subsection{Joining Process}

For the joining process, a custom-built apparatus is used. This joining apparatus is using infrared radiation to heat the CFRT samples and features a pneumatic cylinder to apply the force required to press the metal pin into the locally molten CFRT sample.

The utilized Infrared spot type 600.5100.1 (Optron Infrared Systems GmbH, Garbsen, Germany) has a power output of $150 \mathrm{~W}$. It has a focus distance of $50 \mathrm{~mm}$ with a focal spot diameter at the nominal focus distance of $10 \mathrm{~mm}$. The spot radiates in the short wavelength infrared spectrum with a maximum radiation intensity at a wavelength of 1,200 $\mathrm{nm}$. So to achieve a reduction of the irradiated area of the CFRT sample, a mask with a circular opening measuring $8 \mathrm{~mm}$ in diameter is mounted between the Infrared spot and the sample, Fig. 3.

The pneumatic Cylinder ADN-80-25-A-P-A (Festo SE \& Co. KG, Esslingen, Germany) features a piston with a diameter of $80 \mathrm{~mm}$, which results in a theoretical maximum force of about $3.000 \mathrm{~N}$ at an operating pressure of $0.6 \mathrm{MPa}$. At $0.5 \mathrm{MPa}$, the time required to move through the working stroke is measured to a range between $0.0125 \mathrm{~s}$ and $0.0167 \mathrm{~s}$ resulting in an average moving between $1.50 \mathrm{~m} / \mathrm{s}$ and $2 \mathrm{~m} / \mathrm{s}$.
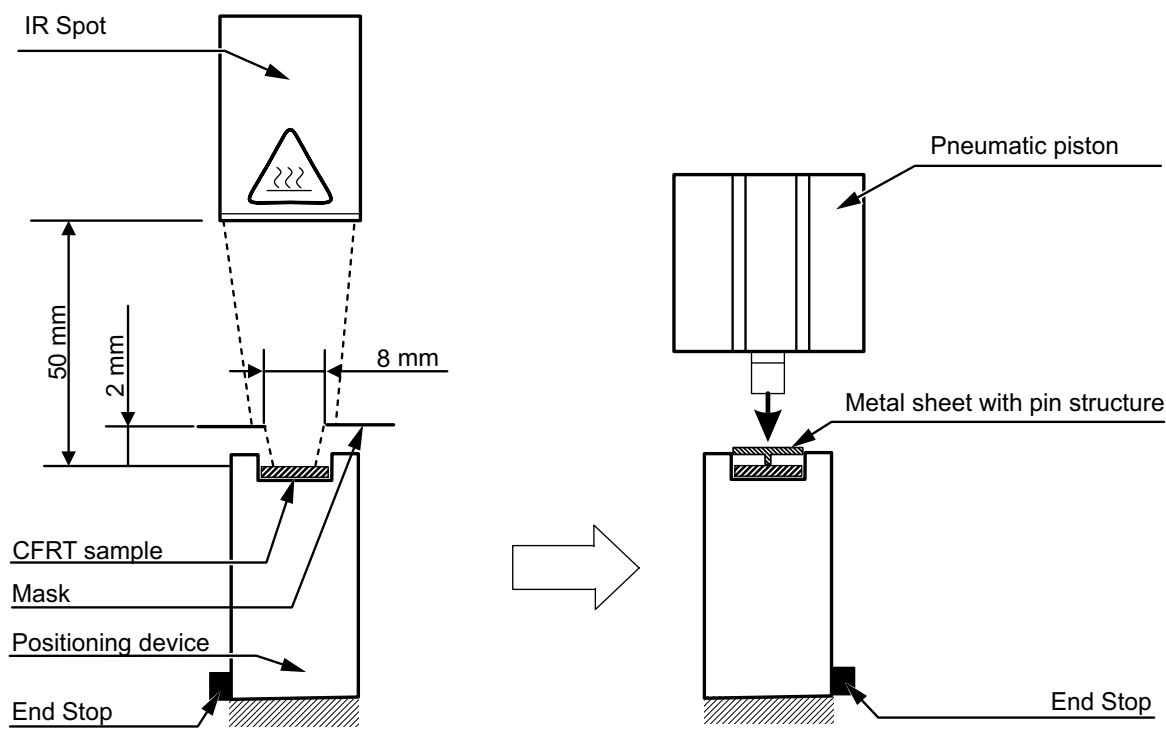

Fig. 3 Joining device with short wave length infrared spot and pneumatic piston (not drawn to scale) 
The process of direct-pin pressing is as follows: First, the CFRT sample is placed in the positioning device, which features a pocket in the size of the CFRT sample to allow for a precise and repeatable positioning under the IR-spot. The positioning device itself is manufactured of Polytetrafluoroethylene (PTFE) in order to reduce conductive heat loss at the lower sample surface (side B). It is reproducibly placed under the IR spot with metallic end stops.

Second, the top side of the CFRT sample (side A) is heated via infrared radiation until the matrix component is locally molten. Thereby, particular attention is paid to a complete melting of the sample across its thickness: for a successful joining operation, it is inevitable that not only the side $\mathrm{A}$ is heated above the melt peak temperature but that also side B, which is facing the positioning device is molten. The latter is required to allow fibers and matrix to be displaced in consequence of the pin insertion. Therefore, for every different setting, it is necessary to conduct preliminary tests to determine the ideal heating time and power as it is described in Sect. 2.6.

Third, the positioning device holding the sample is manually placed under the pneumatic piston. Again, positioning is defined with the help of metallic end stops. Following, the cold sheet featuring the pin structure is placed in a second pocket in the positioning device in such a way that the pin is located in the middle of the heated area on the CFRT sample.

Fourth, the pin is pressed into the CFRT sample via the pneumatic piston. The piston head has a diameter of $14 \mathrm{~mm}$ and applies the force along the pin and normally to the molten area of the CFRT sample. The pneumatic pressure is controlled to two different settings: $0.1 \mathrm{MPa}$ and $0.5 \mathrm{MPa}$, resulting in a force of $500 \mathrm{~N}$ respectively $2.500 \mathrm{~N}$. Figure 4 shows an exemplary disassembled CFRT sample and corresponding metal sample with pin structure as well as a joined hybrid part (left side) and a detailed image of a cylindrical pin with a diameter of $1.50 \mathrm{~mm}$ (right side). The locally heated zone of the CFRT sample can be clearly seen as circular dark zone on the CFRT component of the joined hybrid part.

In pre-trials, the time difference between completion of the heating and completion of the joining operation has been measured to a range of 5 and up to $7 \mathrm{~s}$. Consequently, it is required that the matrix material remains in a molten state within this time span which is verified in the Sections 2.6 and 3.2.

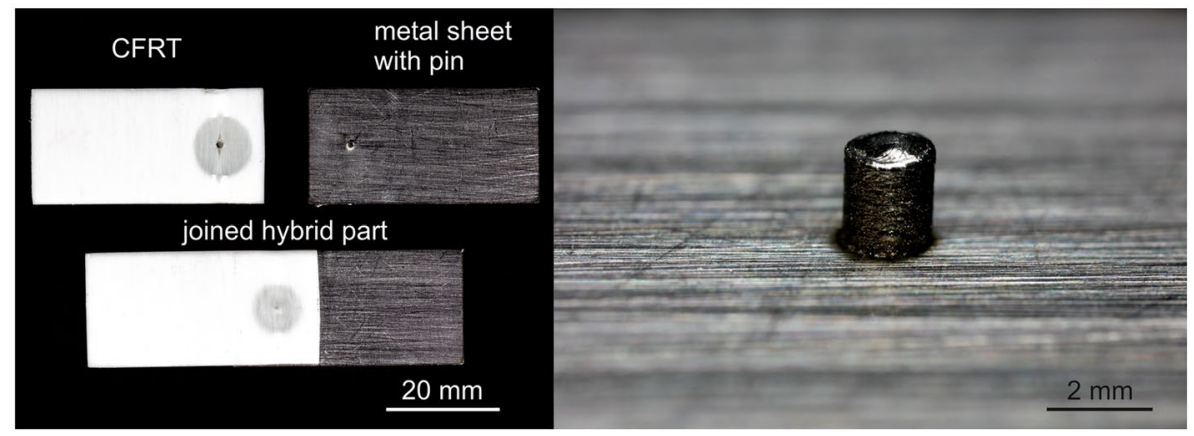

Fig. 4 CFRT sample and metal sample with pin structure (top left) and joined CFRT-metal hybrid part (bottom left) and a detail image of a cylindrical pin with a diameter of $1.50 \mathrm{~mm}$ (right) 
Finally, the force is kept constant at $500 \mathrm{~N}$ respectively $2.500 \mathrm{~N}$ for $30 \mathrm{~s}$ in order to allow the CFRT-sample to sufficiently cool down. After this holding time of $30 \mathrm{~s}$, the force is removed and the CFRT-metal hybrid sample is removed from the positioning device.

\subsection{Process Temperature Control}

To determine the heating parameters, which are defined by the power setting of the infrared spot and the time of IR exposure, a series of heating pre-trials is conducted. Since only one side of the sample is heated via IR-radiation, a temperature gradient between the heated side $\mathrm{A}$ and the down facing side $\mathrm{B}$ can be expected. Therefore, it is required to reach a sufficient temperature on side B to melt the matrix whilst not overheating and therefore thermally damaging side A. Furthermore, it is necessary, that no premature crystallization takes place, before the pin is pressed into the sample. Therefore, it needs to be ensured that after the changeover time of 5-7 s the temperature on both sides does not drop under a certain minimum joining temperature. The minimum melting and minimum joining temperature are defined to $175^{\circ} \mathrm{C}$ respectively $135^{\circ} \mathrm{C}$ based on a DSC measurement of the CFRT samples, which is shown in Fig. 5.

In order to measure the temperature of the sample on side $\mathrm{A}$ and $\mathrm{B}$, two $\mathrm{Ni}-\mathrm{CrNi}$ type $\mathrm{k}$ thermocouples according to DIN EN 60,584-1 are used [32]. The thermocouples are contacting the CFRT sample's surface is the in the middle of the circularly heated area. The acquired data is recorded using a custom DASYLab script (version 5.1, National Instruments, Austin (Texas), United States of America).

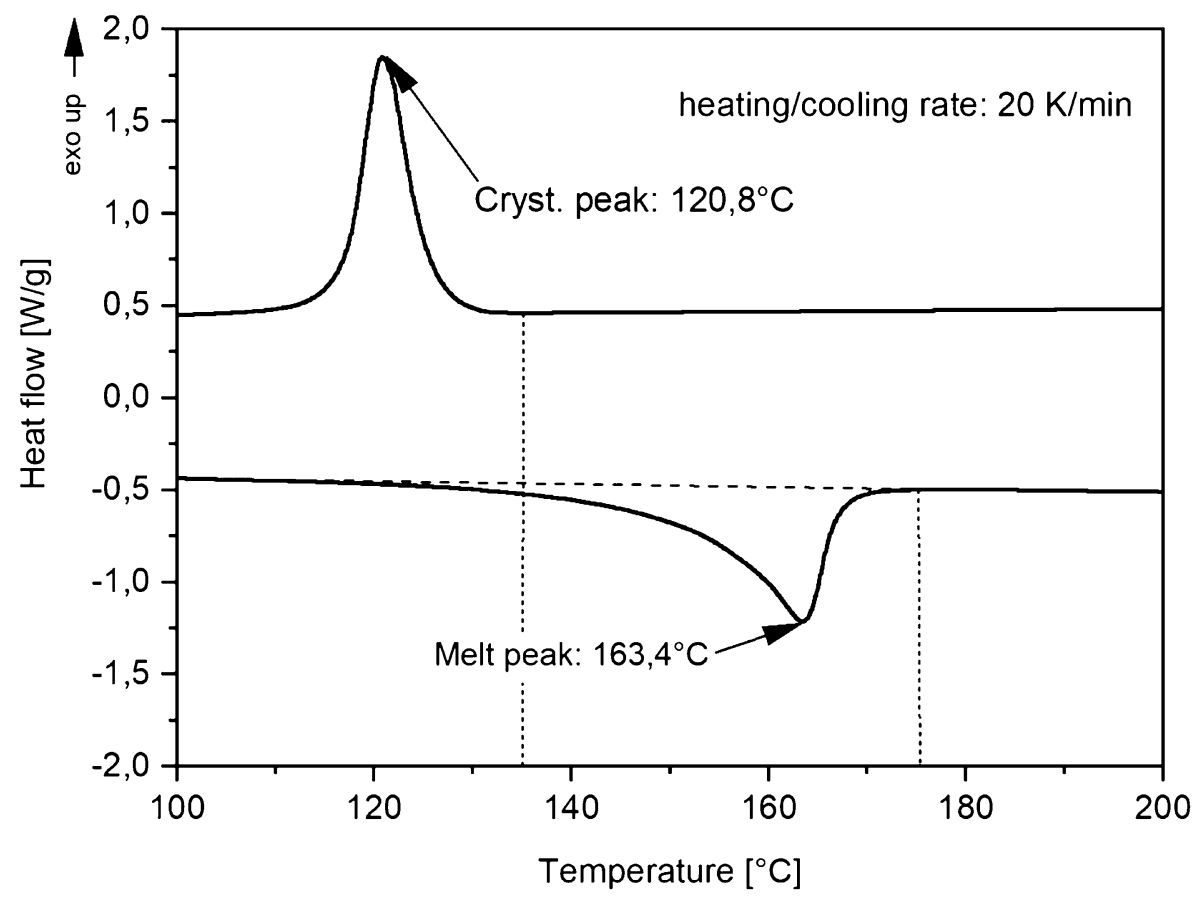

Fig. 5 DSC measurement of CFRT samples with a heating and cooling rate of $20 \mathrm{~K} / \mathrm{min}$ 
The procedure is structured in two stages. In the first step, different power settings are experimentally examined to determine a setting, which leads to a temperature above the minimum melting temperature on side B while avoiding any signs of thermal degradation, such as smoke development or severe discoloring and blackening of the sample, on side A. In the second step, the cool down behavior of the sample is examined to define the available time window where a joining operation is possible. Therefore, the time span until on either side $\mathrm{A}$ or side $\mathrm{B}$ the measured temperature is below the minimum joining temperature is determined.

In the first step, power settings of $28 \%, 30 \%, 32 \%$, and $35 \%$, corresponding to $42 \mathrm{~W}$, $45 \mathrm{~W}, 48 \mathrm{~W}$, and $52.5 \mathrm{~W}$ are evaluated with three repetitions per setting. The sample is heated until a surface temperature of $300^{\circ} \mathrm{C}$ is reached on side $\mathrm{A}$, at which the IR radiation is turned off to avoid thermal degradation of the samples. The obtained data is then used to determine the power settings of the IR-spot as well as the heating time for step two.

In the second step, four measurements are conducted with the previously determined parameter set, consisting of the final power setting and heating time including the cool down phase. In order to consider forced convection during the transition between the heating and joining position, which generally leads to a faster cooling rate, the sample is also moved from the heating position to the joining position as in the actual joining process.

\subsection{Stereo Microscopic Sample Preparation}

Geared toward the investigation of the fiber orientation in the X/Y plane, the CFRT samples are examined using transmitted light microscopy. The analyses are conducted with a stereo microscope of the type Discovery V12 and a microscopy camera of the type Axio Cam MRc5 (both Carl Zeiss Microscopy GmbH, Jena, Germany).

Before microscopic examination, the metallic component including the pin structures are removed from the samples. Since the chosen pin geometries create no undercut, this is relatively easy to achieve by pulling the pin out in the opposite direction of the press-inoperation with the use of a minor force. This leaves a clearly visible pin hole in the sample.

Since the CFRT-samples are naturally colored, the samples are translucent and following, the glass fibers can be identified with transmitted light microscopy without the need to create micro sections prior the examination and fiber rich areas can be identified as dark zones while matrix rich areas appear as bright zones in the image.

In order to quantify the influence of the different pin geometries on the fiber rearrangement a custom MATLAB (MathWorks Inc., Nattick MA., USA) script is used, which determines the average angle of transition between fiber rich zones and the wedgeshaped matrix rich zones based on the stereo microscopic images. Therefore, the stereo microscopic images are first divided into 4 quarter sections which are assessed individually (see also Fig. 7). Each section is transformed into greyscale matrices, which are assessed row for row. For each row, the grey scale values are filtered with a moving average filter to remove discordant values, the derivative of the brightness value is calculated, and the maximum and minimum values of the derivative are determined. Since in the assessed images fiber rich zones appear dark and matrix rich zones appear bright, the maximum and minimum of the derivative of the brightness value mark the position of the transition between matrix rich and fiber rich zones for every row. The obtained row-wise coordinates of the transition between both zones are then linearly fitted to obtain the transition vector and the corresponding angle in relation to the y-axis of the resulting linear function is determined as the transition angle. 
In order to investigate both the influence of tip geometry as well as pin diameter all pin types described in Sect. 2.2 are examined. This procedure is conducted for three pins per pin type on both matrix rich zones, each with two transition vectors, so that for the calculation of the average transition angle twelve sections per pin type can be evaluated with the automated Matlab script. Since in the initial state the fiber have an angle of approximately $0^{\circ}$ in relation to the $y$-axis a steeper angle is a sign for a more pronounced fiber distortion.

\subsection{Micro-computer-tomography}

For the micro-computer-tomography $(\mu \mathrm{CT})$ analysis, the samples are fixed in a rotating mount to allow different viewing angles during the scans, which allow a volume reconstruction basing on the created scans. The $\mu \mathrm{CT}$ analyses are conducted with a micro-computertomograph of the type sub $\mu$-CT (Fraunhofer Institute for Integrated Circuits (IIS) e.V., Erlangen, Germany). All sample scans are sighted in detail, following the path of individual fibers and analyzing them for the fiber rearrangement resulting from the joining process as well as potential breakage, indicated by sudden shifts in direction, internal open ends or sudden voids.

\section{Results}

\subsection{Dimensional Accuracy And Surface Roughness Of Metal Pins}

The laser scanning measurements reveal a relatively accurate reproduction of the planned pin geometries in the PBF-LB process. The accuracy of powder-based additive manufacturing processes depends on various process influencing variables. For example, both the surface morphology [33] and the thermal distortion [34] have an influence on the dimensional accuracy of the components. When investigating the influence of the process parameters on the quality and mechanical properties of additive-manufactured 316L, Delgado et al. [35] found that the building direction of the components has an influence on the accuracy. Here the achieved accuracy was between $1.5-3.0 \%$. In Table 1 the average height and average diameter and corresponding standard deviations per pin type are shown. Generally, the geometrical accuracy with a maximum average deviation of $+0.05 \mathrm{~mm}$ in height for pins with $1.50 \mathrm{~mm}$ in diameter and $120^{\circ}$ tip angle is small. The average percentage deviations of the height from the target geometry are therefore in the range of $-1.67 \%-2.78 \%$.

The maximum average deviation in diameter is $+0.03 \mathrm{~mm}$ for pins with $1.50 \mathrm{~mm}$ in diameter and $60^{\circ}$ tip angle as well as pins with $1.25 \mathrm{~mm}$ in diameter and $60^{\circ}$ tip angle. This results in an average deviation of the diameter from the nominal geometry of $1 \%-2.4 \%$, which is consistent with the manufacturing precision in [35].

On the cylinder jacket, the average Ra values range between $4.9 \mu \mathrm{m}$ and $9.0 \mu \mathrm{m}$ and the average $\mathrm{Rz}$ values range between $26.7 \mu \mathrm{m}$ and $48.9 \mu \mathrm{m}$ (compare Table 2).

Table 2 summarizes the results of the surface measurements. In the literature, values for the roughness of additive-manufactured 316L are in the range of $14.89 \mu \mathrm{m}$ [35], approx. $9 \mu \mathrm{m}$ [26] and approx. $8.5 \mu \mathrm{m}$ [25], to name only a selection, whereby these values depend in part strongly on the selected parameters and the angle of inclination of the investigated surfaces. As already explained in the introduction, Cherry et al. [25] examined the effect of different volume energy densities on the roughness of components made of 316L and demonstrated a minimum roughness of about $8.5 \mu \mathrm{m}$ at a volume energy density of $125.4 \mathrm{~J} /$ 
Table 1 Measured actual average height and diameter of every geometry type, $\mathrm{n}=5$

\begin{tabular}{|c|c|c|}
\hline Type & $\begin{array}{l}\text { Measured average } \\
\text { height in mm } \\
\pm \text { Standard devia- } \\
\text { tion in } \mathrm{mm}\end{array}$ & $\begin{array}{l}\text { Measured diameter in } \mathrm{mm} \\
\pm \text { Standard deviation }\end{array}$ \\
\hline $1.00 \mathrm{~mm}$, flat & $\begin{array}{l}1.77 \\
\pm 0.03( \pm 1,7 \%)\end{array}$ & $\begin{array}{l}1.01 \\
\pm 0.06( \pm 5,9 \%)\end{array}$ \\
\hline $1.00 \mathrm{~mm}, 120^{\circ}$ & $\begin{array}{l}1.82 \\
\pm 0.02( \pm 1,1 \%)\end{array}$ & $\begin{array}{l}1.01 \\
\pm 0.02( \pm 2,0 \%)\end{array}$ \\
\hline $1.00 \mathrm{~mm}, 90^{\circ}$ & $\begin{array}{l}1.80 \\
\pm 0.02( \pm 1,1 \%)\end{array}$ & $\begin{array}{l}1.02 \\
\pm 0.02( \pm 2,0 \%)\end{array}$ \\
\hline $1.00 \mathrm{~mm}, 60^{\circ}$ & $\begin{array}{l}1.80 \\
\pm 0.02( \pm 1,1 \%)\end{array}$ & $\begin{array}{l}1.02 \\
\pm 0.03( \pm 2,9 \%)\end{array}$ \\
\hline $1.25 \mathrm{~mm}$, flat & $\begin{array}{l}1.79 \\
\pm 0.02( \pm 1,1 \%)\end{array}$ & $\begin{array}{l}1.26 \\
\pm 0.02( \pm 1,6 \%)\end{array}$ \\
\hline $1.25 \mathrm{~mm}, 120^{\circ}$ & $\begin{array}{l}1.82 \\
\pm 0.04( \pm 2,2 \%)\end{array}$ & $\begin{array}{l}1.25 \\
\pm 0.03( \pm 2,4 \%)\end{array}$ \\
\hline $1.25 \mathrm{~mm}, 90^{\circ}$ & $\begin{array}{l}1.80 \\
\pm 0.04( \pm 2,2 \%)\end{array}$ & $\begin{array}{l}1.26 \\
\pm 0.02( \pm 1,6 \%)\end{array}$ \\
\hline $1.25 \mathrm{~mm}, 60^{\circ}$ & $\begin{array}{l}1.82 \\
\pm 0.05( \pm 2,7 \%)\end{array}$ & $\begin{array}{l}1.28 \\
\pm 0.02( \pm 1,6 \%)\end{array}$ \\
\hline $1.50 \mathrm{~mm}$, flat & $\begin{array}{l}1.81 \\
\pm 0.05( \pm 2,8 \%)\end{array}$ & $\begin{array}{l}1.52 \\
\pm 0.03( \pm 2,0 \%)\end{array}$ \\
\hline $1.50 \mathrm{~mm}, 120^{\circ}$ & $\begin{array}{l}1.85 \\
\pm 0.04( \pm 2,2 \%)\end{array}$ & $\begin{array}{l}1.52 \\
\pm 0.02( \pm 1,3 \%)\end{array}$ \\
\hline $1.50 \mathrm{~mm}, 90^{\circ}$ & $\begin{array}{l}1.82 \\
\pm 0.05( \pm 2,7 \%)\end{array}$ & $\begin{array}{l}1.52 \\
\pm 0.02( \pm 1,3 \%)\end{array}$ \\
\hline $1.50 \mathrm{~mm}, 60^{\circ}$ & $\begin{array}{l}1.81 \\
\pm 0.09( \pm 5,0 \%)\end{array}$ & $\begin{array}{l}1.53 \\
\pm 0.02( \pm 1,3 \%)\end{array}$ \\
\hline
\end{tabular}

$\mathrm{mm}^{3}$. The parameters used to expose the envelope of the pin structures yield a volume energy density of $133 \mathrm{~J} / \mathrm{mm}^{3}$. The volume energy densities are thus in a comparable range and the $\mathrm{Ra}$ values measured on the pin jacket are also comparable. However, the values of $4.9 \mu \mathrm{m}$ measured for the pin-structure with a $1 \mathrm{~mm}$ diameter and a tip angle of $90^{\circ}$ are also below the values in the literature. Nevertheless, when considering the short length of measurement of $400 \mu \mathrm{m}$ used in the present study, which often leads to a lower measured surface roughness than measurements, made according to DIN-EN ISO 4288, the measured roughness would likely be higher.

Why the roughness values of the flat pin structures are up to $4.14 \mu \mathrm{m}$ higher than those of the other pin structures cannot be easily explained from a process-technical point of view, since all pin structures were manufactured with the same process parameters. However, the values of the flat pin structures show a significantly higher standard deviation than the other pin structures. One reason for this could be a higher number of adhering powder particles on the surface, as can be seen in Fig. 2. These partly fused powder particles can also explain the high $\mathrm{Rz}$ values, which range from $26.7 \mu \mathrm{m}$ to $48.9 \mu \mathrm{m}$. When compared to other manufacturing processes such as turning (Ra typically around $2 \mu \mathrm{m}$ ) and cold drawing (Ra typically around $1.6 \mu \mathrm{m}$ ) [23] the surface roughness is still relatively high. Also in comparison to Cold Metal transfer (CMT) pins, the roughness is significantly higher. As an indication, Ryan et al. report surface roughness values between 0.7 to $1.0 \mu \mathrm{m}$ for different wires used for the CMT-process [24]. 
Table 2 Measured $\mathrm{Ra}$ and $\mathrm{Rz}$ surface roughness on cylinder jacket, $\mathrm{n}=5$

\begin{tabular}{|c|c|c|}
\hline Type & $\begin{array}{l}\text { Ra Cylinder jacket in } \mu \mathrm{m} \\
\pm \text { standard deviation } \mu \mathrm{m}\end{array}$ & $\begin{array}{l}\text { Rz Cylinder jacket in } \mu \mathrm{m} \\
\pm \text { standard deviation in } \mu \mathrm{m}\end{array}$ \\
\hline $1.00 \mathrm{~mm}$, flat & $\begin{array}{l}9.01 \\
\pm 3.54( \pm 39.3 \%)\end{array}$ & $\begin{array}{l}48.87 \\
\pm 24.26( \pm 49.6 \%)\end{array}$ \\
\hline $1.00 \mathrm{~mm}, 120^{\circ}$ & $\begin{array}{l}4.87 \\
\pm 0.71( \pm 14.6 \%)\end{array}$ & $\begin{array}{l}26.81 \\
\pm 4.30( \pm 16.0 \%)\end{array}$ \\
\hline $1.00 \mathrm{~mm}, 90^{\circ}$ & $\begin{array}{l}4.92 \\
\pm 0.53( \pm 10.8 \%)\end{array}$ & $\begin{array}{l}28.58 \\
\pm 4.84( \pm 16.9 \%)\end{array}$ \\
\hline $1.00 \mathrm{~mm}, 60^{\circ}$ & $\begin{array}{l}5.07 \\
\pm 0.83( \pm 16.4 \%)\end{array}$ & $\begin{array}{l}27.13 \\
\pm 3.52( \pm 13.0 \%)\end{array}$ \\
\hline $1.25 \mathrm{~mm}$, flat & $\begin{array}{l}5.18 \\
\pm 0.63( \pm 12.2 \%)\end{array}$ & $\begin{array}{l}28.39 \\
\pm 2.53( \pm 8.9 \%)\end{array}$ \\
\hline $1.25 \mathrm{~mm}, 120^{\circ}$ & $\begin{array}{l}5.88 \\
\pm 1.59( \pm 27.0 \%)\end{array}$ & $\begin{array}{l}32.97 \\
\pm 11.31( \pm 34.3 \%)\end{array}$ \\
\hline $1.25 \mathrm{~mm}, 90^{\circ}$ & $\begin{array}{l}6.04 \\
\pm 1.75( \pm 29.0 \%)\end{array}$ & $\begin{array}{l}32.96 \\
\pm 8.12( \pm 24.6 \%)\end{array}$ \\
\hline $1.25 \mathrm{~mm}, 60^{\circ}$ & $\begin{array}{l}4.98 \\
\pm 0.82( \pm 16.5 \%)\end{array}$ & $\begin{array}{l}30.56 \\
\pm 5.11( \pm 16.7 \%)\end{array}$ \\
\hline $1.50 \mathrm{~mm}$, flat & $\begin{array}{l}5.25 \\
\pm 1.15( \pm 21.9 \%)\end{array}$ & $\begin{array}{l}31.85 \\
\pm 5.93( \pm 18.6 \%)\end{array}$ \\
\hline $1.50 \mathrm{~mm}, 120^{\circ}$ & $\begin{array}{l}4.96 \\
\pm 0.66( \pm 13.4 \%)\end{array}$ & $\begin{array}{l}26.74 \\
\pm 2.46( \pm 9.2 \%)\end{array}$ \\
\hline $1.50 \mathrm{~mm}, 90^{\circ}$ & $\begin{array}{l}5.16 \\
\pm 1.09( \pm 21.1 \%)\end{array}$ & $\begin{array}{l}28.08 \\
\pm 5.33( \pm 19.0 \%)\end{array}$ \\
\hline $1.50 \mathrm{~mm}, 60^{\circ}$ & $\begin{array}{l}8.22 \\
\pm 1.67( \pm 20.3 \%)\end{array}$ & $\begin{array}{l}47.54 \\
\pm 6.00( \pm 12.6 \%)\end{array}$ \\
\hline
\end{tabular}

\subsection{Process Temperatures}

The most suitable parameter set was determined at a power setting of $30 \%$ and a heating time of $400 \mathrm{~s}$. Other settings either did not lead to a sufficient temperature on side B or showed surface temperatures over $300^{\circ} \mathrm{C}$ on side A before side B could be heated over the minimum melting temperature defined in Sect. 2.6. Figure 6 illustrates the heating as well as cooling behavior with the final parameter set.

As the average final temperature on side $\mathrm{A}$ is measured to $285^{\circ} \mathrm{C}$, it is possible that thermal degradation takes place to a certain degree even when considering the relatively short time span at which the sample is heated to such a high temperature.

No optical signs of thermal decomposition, such as brown or dark spots or significant smoke emissions could be observed. In order to verify this, TGA tests under nitrogen atmosphere with a heating rate of $10 \mathrm{~K} / \mathrm{min}$ have been conducted with a virgin sample as well as a sample that was extracted from center of the heated zone. The used heating rate is comparable to the actual heating process after the initial rapid heating in the first $100 \mathrm{~s}$ : Both samples showed almost identical results with a first mass loss at a temperature of around $340{ }^{\circ} \mathrm{C}$ which is well above the measured $285{ }^{\circ} \mathrm{C}$ on Side A during IR heating. It is possible that some oxidation takes place directly on the surface of the sample. However, this is not expected to significantly influence the fiber displacement. 


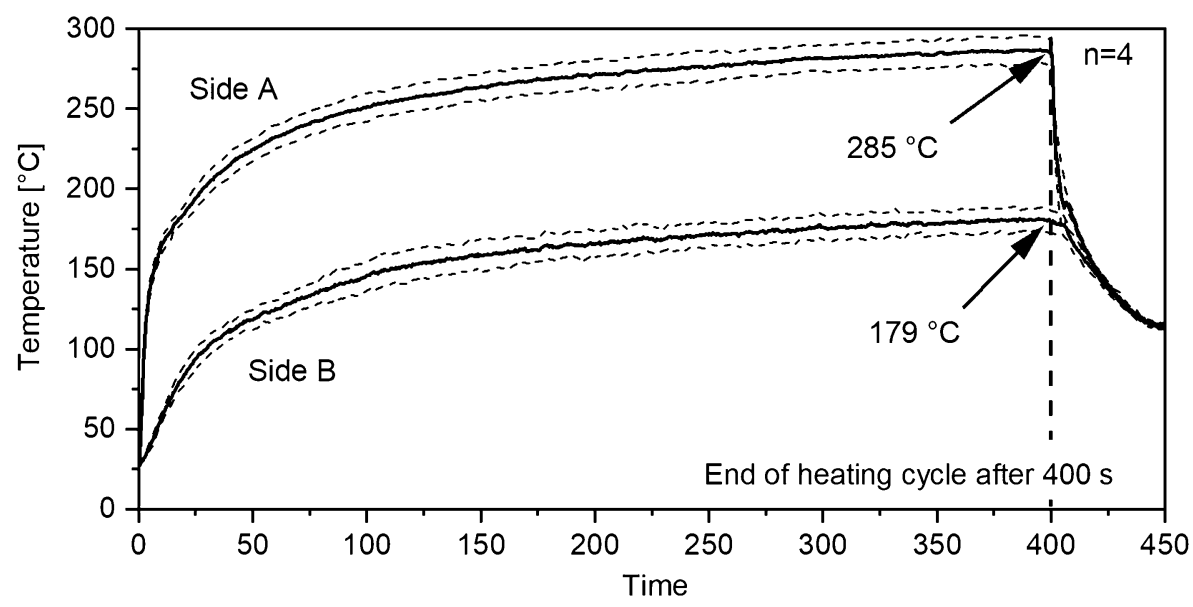

Fig. 6 Illustration of temperature profile during heating cycle at a power setting of $30 \%$ or $45 \mathrm{~W}$. Solid lines representing the average temperature over four samples while dashed lines representing the standard deviation

After the changeover time, which lasts between 5 and $7 \mathrm{~s}$ (compare 2.5), the average temperature on side A ranges between $192^{\circ} \mathrm{C}$ with a standard deviation of $19.3^{\circ} \mathrm{C}$ (after $5 \mathrm{~s}$ ) and $190^{\circ} \mathrm{C}$ with a standard deviation of $5.2^{\circ} \mathrm{C}$ (after $7 \mathrm{~s}$ ). On side $\mathrm{B}$, the average temperature ranges between $177^{\circ} \mathrm{C}$ with a standard deviation of $7.0^{\circ} \mathrm{C}$ (after $5 \mathrm{~s}$ ) and $174^{\circ} \mathrm{C}$ with a standard deviation of $5.1^{\circ} \mathrm{C}$ (after $7 \mathrm{~s}$ ). These temperatures are well above the minimum joining temperature, even when considering the measured standard deviation. Therefore, a sufficient fiber flexibility can be expected during the joining operation after the change over time, which typically lasts up to $7 \mathrm{~s}$.

\subsection{Fiber Orientation}

As described in Sect. 2.5, two different operating pressures (0.1 $\mathrm{MPa}$ and $0.5 \mathrm{MPa})$ are used. Since only the higher pressure of $0.5 \mathrm{MPa}$ leads to satisfying joining results, the following results are based on this operating pressure. The effects of a low joining and reconsolidation force are discussed in Sect. 3.4.

Independent of the pin diameter and tip geometry, similar fiber rearrangement phenomena can be observed, although the degree of fiber displacement, especially in the X/Y plane, differs between pin types. When investigating stereo microscopic images in the $\mathrm{X} / \mathrm{Y}$ plane, Pin insertion leads to the following effects: Next to the pinhole, a matrix-rich wedge-shaped zone can be observed as a bright area with no visible fibers. In contrast to that, dark zones can be seen along the $\mathrm{X}$-axis in direct proximity to the formed pinhole (compare. Figure 7). It is suggested that these dark zone indicate locally increased fiber concentrations.

During the investigation of the average transition angles it shows, that not every investigated quarter section can be recognized with the automated Matlab script due to partially damaged surfaces of the CFRT samples and/or insufficient contrast of the investigated images. The faulty quarter sections are excluded from the evaluation so that in total a range between six and twelve quarter section per pin type are included in the evaluation. The standard deviation per pin type is calculated from the average value of each individual pin. 


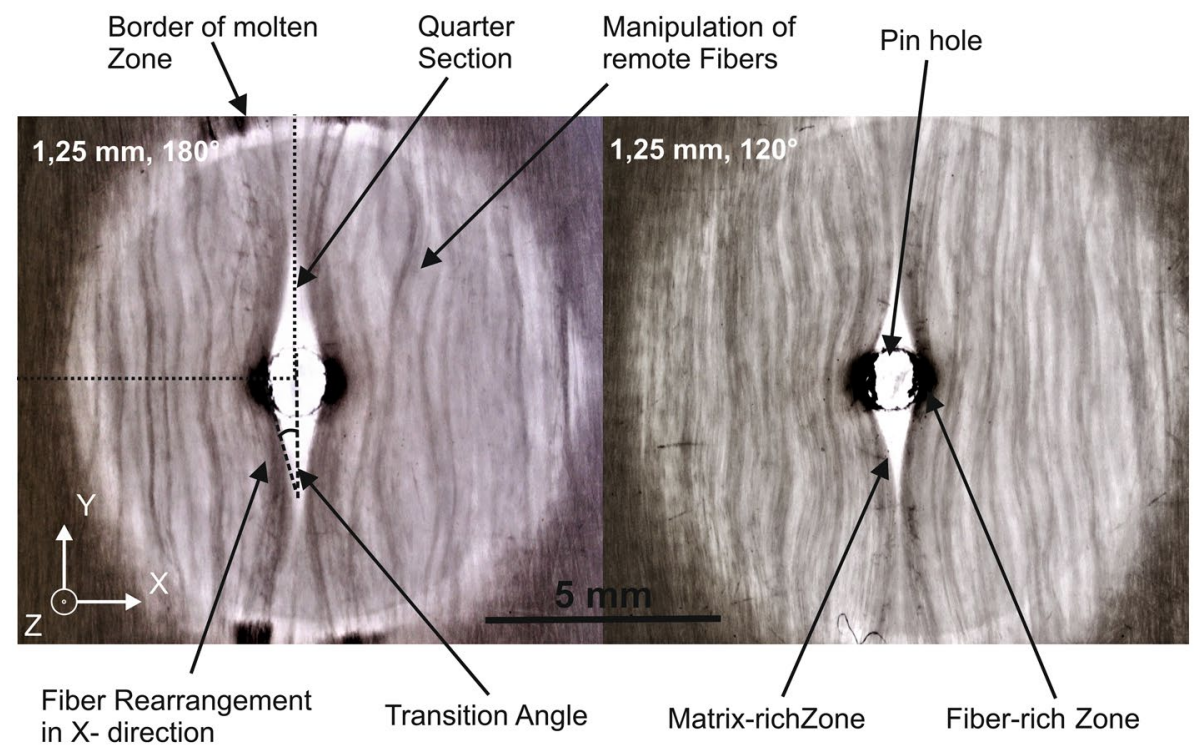

Fig. 7 Stereo microscopic transmitted light image of a CFRT sample after joining with 5 bar / $2500 \mathrm{~N}$ and removal of the pin with $1.25 \mathrm{~mm}$ pin diameter and a tip angle of $180^{\circ}$ (left) and $120^{\circ}$ (right)

Figure 8 summarizes the results based on the pin diameter and the tip geometry. The results show a clear dependency of the pin diameter on the transition angle which is especially pronounced between pins with a diameter of $1.25 \mathrm{~mm}$ and $1.50 \mathrm{~mm}$. Between pins with $1.00 \mathrm{~mm}$ and $1.25 \mathrm{~mm}$ in diameter, only a slight tendency towards larger transition angle with increasing pin diameter can be seen. The results are summarized in Fig. 8.

In the following, the transition angles are presented in this order: mean value of the compared pin type in degree, \pm standard deviation in degree / standard deviation in $\%$ of the mean value. For pins with a diameter of $1.00 \mathrm{~mm}$, the average transition angle ranges from $12.2^{\circ} \pm 2.1^{\circ} / 17.2 \%$ ( $180^{\circ}$ tip angle) over $14.2^{\circ} \pm 5.0^{\circ} / 35.2 \%\left(120^{\circ}\right.$ tip angle $)$ and $13.17^{\circ} \pm 1.6^{\circ} / 12.1 \%$ ( $90^{\circ}$ tip angle) to $17.35^{\circ} \pm 3.8^{\circ} / 21.9 \%$ (60 tip angle). For pins with a diameter of $1.25 \mathrm{~mm}$ the average transition angles are as follows: $15.2^{\circ} \pm 1.4^{\circ} / 9.2 \%$ $\left(180^{\circ}\right.$ tip angle), $15.4^{\circ} \pm 2.0^{\circ} / 13 \%$ (120 tip angle), $14.9^{\circ} \pm 1.4^{\circ} / 9.4 \%$ (90 $0^{\circ}$ tip angle) and $15.7^{\circ} \pm 4.8^{\circ} / 30.6 \%$ (60 tip angle). Pins with a diameter of $1.5 \mathrm{~mm}$ show significantly larger average transition angles of $31.6^{\circ} \pm 10.9^{\circ} / 35.5 \%$ (180 $0^{\circ}$ tip angle), $30.9^{\circ} \pm 2.8^{\circ}$ / $9.1 \%$ ( $120^{\circ}$ tip angle), $30.6^{\circ} \pm 2^{\circ} / 6.5 \%$ (90 tip angle) and $29.5^{\circ} \pm 3^{\circ} / 10.2 \%$.

Generally, it can be concluded that no systematic dependency between different tip angles and the measured transition angles can be seen: While pins with a diameter of $1.5 \mathrm{~mm}$ show a slightly lower transition angle with a steep $60^{\circ}$ tip angle, pins with a diameter of $1.0 \mathrm{~mm}$ and $1.25 \mathrm{~mm}$ show the highest transition with a $60^{\circ}$ tip angle. Generally the differences between different tip angles lie within the range of the standard deviations.

Since a larger transition angle can be interpreted as a sign for increased fiber displacement in X-direction (compare Fig. 7) and consequently larger fiber undulation, it can be expected that a smaller pin diameter is beneficial to the joint quality in means of fiber distortion, potential fiber breakage and ultimately also joint strength.

The question why certain pin geometries show noticeably higher standard deviations than others cannot be completely explained at this point. One reason for this could be that 


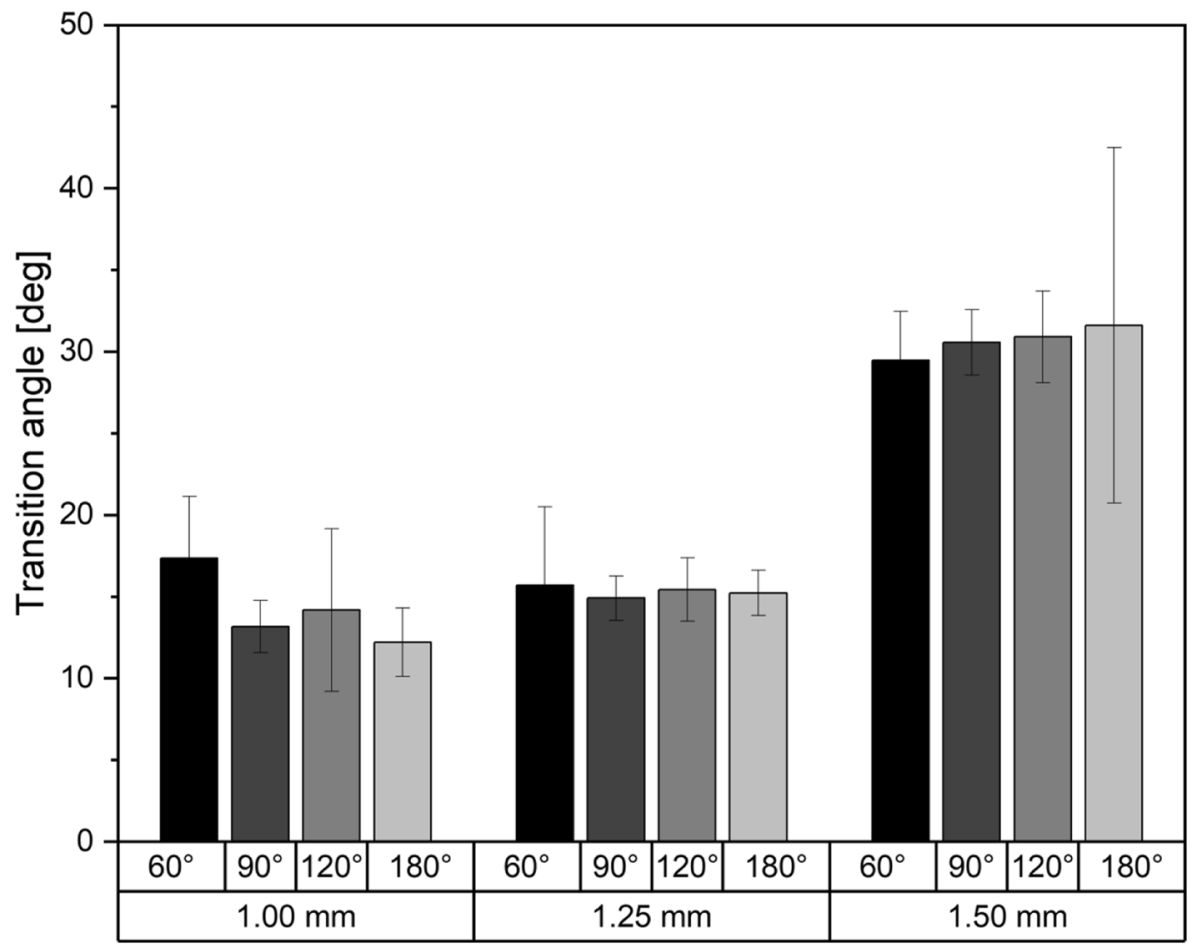

Fig. 8 Comparison of average transition angle based on Pin Diameter with different pin diameters and tip angles

the evaluation script does not recognize every transition angle accurately. A second explanation for this is the limited repeatability of the manual execution of the joining process: a difference of two seconds in joining time between two joining operations could lead to increased matrix viscosity in one sample and therefore a difference in fiber displacement. To address this issue, for future studies it is planned to improve the evaluation method in means of recognition quality as well as the joining process in means of an automated joining process with improved repeatability.

Similar to the stereo microscopic transmitted light images, the $\mu \mathrm{m}$ computer tomographic images show fiber rearrangements, which are mostly independent from the pin geometry. Measurements in the $\mathrm{X} / \mathrm{Y}$ plane show the same phenomena as the transmitted light stereo microscopic images.

In the $\mathrm{Y} / \mathrm{Z}$ plane, the most notable phenomenon is a significant fiber displacement in the direction of the press-in-operation (Z-direction) accompanied by fiber compression between the tip of the inserted pin and the surface of the CFRT sample as it was already discovered in [20]. This fiber displacement can be observed for all investigated pin-geometries with no fundamental differences between different diameters and tip angles. However, the fiber displacement follows the shape of the tip geometry and therefore, the distance of fiber displacement in Z-direction differs depending on the tip geometry and the observed sectional plane. Pins with a flat tip lead to the highest fiber compaction while pins with a steeper tip angle only lead to a high compaction directly under the middle axis of the pin 
and decreasing fiber compaction with the observed plane moving further away from the middle axis. Kraus et al. suggested that the fiber displacement is primarily a result of the used pin with a flat head [20]. This assumption could not be confirmed since the fiber displacement in Z-direction could also be observed with a relatively steep tip angle of $60^{\circ}$. A possible explanation for this observation might be, that the insertion depth of $1.8 \mathrm{~mm}$ is not sufficient for a positive effect of a tapered pin tip. In Y-direction, next to the pin hole, the fiber-free and matrix rich zone, which can also be observed in the stereomicroscopic images, can be seen.

In the $\mathrm{Z} / \mathrm{X}$ plane it can be seen, that the fibers closely follow the shape of the inserted pin with an increased fiber density close to the pin (brighter areas). No systematic differences between different pin tip geometries can be seen besides the fact that a stronger tapering of the pin generally leads to less fiber displacement, which can be explained with the smaller volume of a tapered pin in comparison to a cylindrical pin that consequently leads to less displacement.

Figure 9 shows exemplary $\mu \mathrm{m}-\mathrm{CT}$ images in the $\mathrm{Z} / \mathrm{Y}$ as well as $\mathrm{Z} / \mathrm{X}$ plane of CFRT samples with tip angles ranging from $180^{\circ}$ to $60^{\circ}$ and a pin diameter of $1.25 \mathrm{~mm}$. A significant fiber displacement in Z-direction can be observed for all investigated tip angles.

In comparison to Hufenbach et al., the fiber displacement in the $\mathrm{X} / \mathrm{Y}$ plane can also be observed for fibers, which have a distance of more than $2 \mathrm{~mm}$ from the inserted pin while with the thermoactivated pinning technology a fiber displacement can only be seen on a very small scale. This can be explained with the comparably small molten zone during thermoactivated pinning, which only measures few tenths of a millimeter and therefore significantly limits flexibility of more remote fibers. Furthermore, the woven fabric used by Hufenbach et al. might limit the fiber flexibility compared to the unidirectional CFRT tapes used in this paper and consequently impedes the fiber displacement [17].

When compared to [18] and [27] which both investigate the hole molding in twill weave glass fiber reinforced polypropylene, the resulting fiber displacement with distinct matrix rich and fiber rich areas is basically similar. However, there are also significant differences visible. First, in [18] a pattern of four matrix rich zones with an angle of $90^{\circ}$ between each matrix rich zone can be seen whereas in the direct pin pressing process only two matrix

Fig. 9 Exemplary $\mu \mathrm{m}$ CT image of CFRT samples after joining with 5 bar / $2500 \mathrm{~N}$ and removal of the pin with $1.25 \mathrm{~mm}$ pin diameter and tip angles ranging from $60^{\circ}$ to $180^{\circ}$

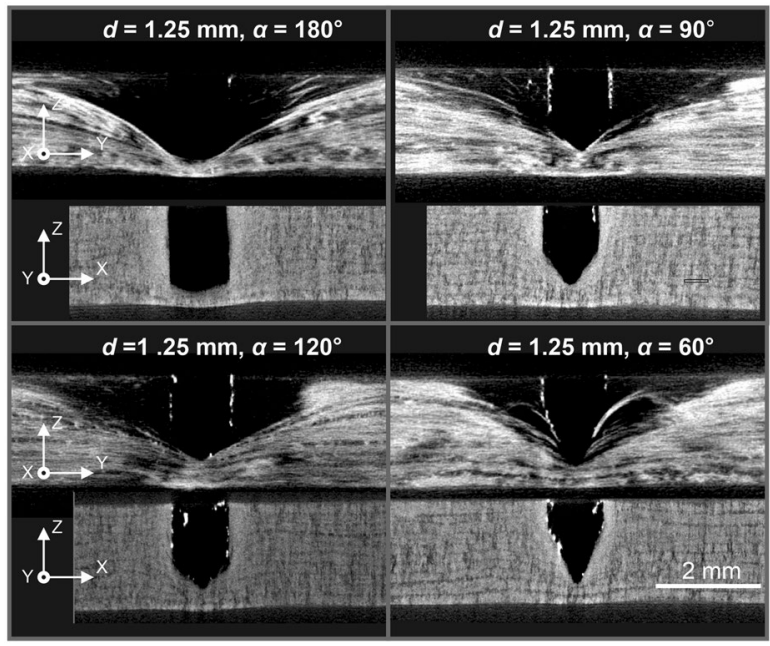


rich zones can be seen. This difference can be explained with the different reinforcements of the investigated samples, where in [18] a bi-axial twill reinforcement is used with fibers oriented in $0^{\circ}$ (Y-axis) and $90^{\circ}$ (X-axis) while in the present study a unidirectionalreinforced sample is used with fibers only being present in $0^{\circ}$. Second, the matrix rich zone in [18] and [27] spans from the molded hole to the border of the molten zone. In the present study, the matrix rich zone does not span as far. Instead, the wedge-shaped zone closes at roughly one third of the distance between pin hole and the border of the molten zone.

Compared to Hufenbach et al., the fiber displacement in Z-direction is more pronounced which can be led back to the different sizes of the molten zones where a lager molten zone leads to a higher fiber flexibility and therefore more distinct fiber displacements. Another potential reason for the pronounced displacement in Z-direction can be found in the comparably high roughness of the additively manufactured pins. Although not exactly specified in the publication of Hufenbach et al., it is likely that the utilized 100Cr6 steel pins are manufactured using either a cold forming or a cutting operation, such as turning. These manufacturing technologies typically lead to lower surface roughness values than measured in Sect. 3.1 [23]. These potentially higher roughness values of the pins might lead to the increased fiber drag in Z-direction when compared to Hufenbach et al. [17].

\subsection{Fiber Orientation Mechanism}

For the purpose of understanding the underlying fiber orientation mechanism, a closer examination of laser scanning topography images from samples with different pneumatic joining pressures of $0.1 \mathrm{MPa}$ and $0.5 \mathrm{MPa}$ and samples from the process temperature control pre trials (see Sect. 2.6), which are heated to joining temperature but are not joined, is conducted. These three samples show phenomena, which can be seen independently from the pin diameter and tip geometry and show characteristic stages of the joining operation.

On the bottom, Fig. 10 shows exemplary laser scanning topography images of the three different stages:

Fig. 10 Three phases of pin direct pin pressing. 1.: heated CFRT sample and locally molten matrix. 2.: inserted pin and resulting displaced fibers in z-direction with void formation. Applied force 500 N 3.: pressure applied on matrix and closed voids with resulting fiber displacement. Piston force 2,500 N

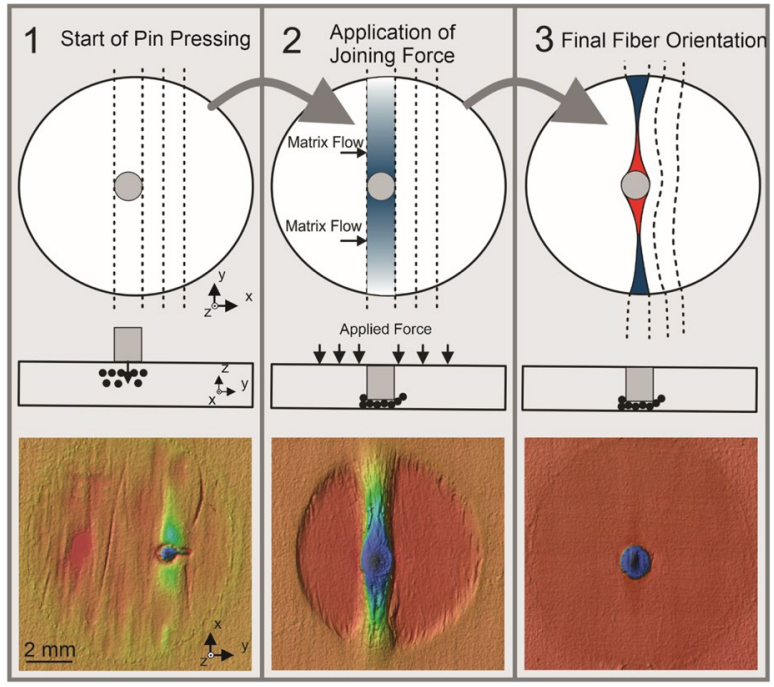


1. In the heated but not joined samples the heated zone can be seen as slightly elevated circular area. Furthermore, irregularities, such individual fibers and sunk spots can be seen.

2. At the sample with a joining force of $500 \mathrm{~N}$, a distinct groove can be seen, spanning on both sides from the pin hole in y-direction to the edge of the heated zone. Generally, the rise of the heated zone is more pronounced than at the previous stage.

3. Samples joined with a force of $2.500 \mathrm{~N}$ appear almost completely flat. The only significant surface defect can be seen in the cavity of the pin hole.

In order to explain the observed phenomena of the surface investigation in this section and the fiber rearrangements discovered in Sect. 3.3, the following three-phase model is proposed:

1. In the first phase, the CFRT sample is locally heated and the matrix is in a molten state. As a result, a certain fiber mobility is given and therefore deconsolidation processes take place, locally resulting in an aperiodic surface and a slight rise of the sample thickness.

2. In the second phase, the pin is pressed into the CFRT sample in z-direction until a complete insertion into the sample is reached. However, in this phase there is only little pressure applied to the molten zone surrounding the actual pin contact area. Following the insertion-motion, fibers are primarily displaced in Z-direction. Due to the high affinity of the molten matrix with the fibers, the matrix is displaced similar to the fibers. The displaced fibers and matrix form two wedge-shaped void zones or grooves in the Y/Z-plane spanning from the edges of the molten area to the inserted pin. Since the volume of the sample is expected to stay almost constant, the displaced volume is accommodated by an increase in thickness of the sample in the molten zone left and right to the edge shaped voids.

3. In the third phase, a homogeneous reconsolidation pressure is applied onto the molten zone. This pressure forces the molten matrix to fill the created void zones and create the matrix-rich zone as pictured in Fig. 7, also affecting the fibers in the molten zone, which follow the matrix flow to a certain degree due to the already mentioned affinity between matrix and fibers. This results in the concave fiber orientation as it can be seen in Fig. 7 and is shown exemplary in Fig. 10.

\section{Conclusion and Outlook}

This study shows a feasible process route of the direct pin pressing process to create continuous fiber reinforced thermoplastics-steel hybrid parts with additively manufactured metallic pins and infrared heating of the CFRT component and a pneumatic piston to create the required joining movement and force. The powder bed fusion process proved as a suitable manufacturing method to create pin shaped structures with good accuracy even for the small investigated dimensions between $1.00 \mathrm{~mm}$ and $1.50 \mathrm{~mm}$ in diameter and $1.80 \mathrm{~mm}$ in height. However, the measured average Ra values between $4.9 \mu \mathrm{m}$ and $9.0 \mu \mathrm{m}$ and the average $\mathrm{Rz}$ values between $26.7 \mu \mathrm{m}$ and $48.9 \mu \mathrm{m}$ are relatively high, what can be led back to the manufacturing process based on a powder as base material.

The microscopic examination of the penetrated CFRT samples shows distinct fiber displacement phenomena, which do not fundamentally vary between different pin geometries. A major fiber displacement in Z-direction can be observed with all investigated tip 
geometries and dimensions. One reason for this pronounced displacement in Z-direction could be seen in the rough surface of the pins, which might lead to increased fiber drag in Z-direction and may avoid fibers slipping off from the tip of the angled pins. The verification of this assumption will be a topic for future studies. In addition to the displacement in $\mathrm{Z}$, a concave displacement in the $\mathrm{X} / \mathrm{Y}$ plane could also be observed. A proposed three-stage model of the fiber displacement mechanism explains the displacement in the $\mathrm{X} / \mathrm{Y}$ plane as a result of a viscoelastic matrix flow which drags fibers into void zones created by the initial fiber displacement in Z-direction.

The in-detail assessment of stereo microscopic transmitted light images of the fiber displacement shows, that the tip geometry of the pin does not have significant influence on the average transition angle and consequently the fiber displacement in the X/Y plane whereas the pin diameter has a significant influence. With increasing pin diameter average the transition angle of cylindrical pins grows from $12.2^{\circ}$ for pins with a diameter of $1.00 \mathrm{~mm}$ over $15.2^{\circ}$ for pins with a diameter of $1.25 \mathrm{~mm}$ to $31.6^{\circ}$ for a diameter of $1.50 \mathrm{~mm}$. Since a small transition angle is a sign for a gentle fiber displacement, it is expected that a smaller pin diameter around $1.00 \mathrm{~mm}$ or $1.25 \mathrm{~mm}$ leads to favorable mechanical properties of the joint and therefore should be preferred for future studies while the tip geometry seems to be of inferior influence. However, the mechanical part behavior is not the focus of this study and will be evaluated in future studies.

In addition, no geometries with undercuts have been investigated yet. The use of pin geometries with undercuts is expected to increase the stability of the multi material joint, as it adds a macro form fit to the joint. When creating joints with undercuts, particular attention has to be paid to the filling of the created undercuts. It would be desirable that the undercuts are filled not only with matrix material, but also with reinforcement fibers to create a strong interlocking joint. Based on the three-stage model of the fiber displacement developed in this study, filling undercuts with matrix material as well as fibers that are displaced in the $\mathrm{X} / \mathrm{Y}$ plane through reconsolidation pressure seems to be possible when sufficient pressure is applied.

For future studies, it is planned to improve the evaluation method of the transition angle in means of recognition quality as well as the joining operation in means of higher automation to achieve higher repeatability.

Authors' Contributions All authors contributed to the study conception and design. Julian Popp built the processing equipment including the joining apparatus. Thomas Papke contributed in processing pin structures on sheet metal by PBF-LB. Material preparation of CFRT components and data collection were performed by Julian Popp. Analysis of the acquired data were performed by Julian Popp and David Römisch. The original draft was written by Julian Popp and David Römisch. Tobias Kleffel contributed in review and editing of the original draft. Dietmar Drummer and Marion Merklein contributed in supervision. All authors read and approved the final manuscript.

Funding Open Access funding enabled and organized by Projekt DEAL. Funded by the Deutsche Forschungsgemeinschaft (DFG, German Research Foundation) - TRR 285 - Project-ID 418701707.

Data Availability The raw data required to reproduce these findings cannot be shared at this time as the data also forms part of an ongoing study.

Code Availability The code required to reproduce these findings cannot be shared at this time as the code also forms part of an ongoing study.

Open Access This article is licensed under a Creative Commons Attribution 4.0 International License, which permits use, sharing, adaptation, distribution and reproduction in any medium or format, as long 
as you give appropriate credit to the original author(s) and the source, provide a link to the Creative Commons licence, and indicate if changes were made. The images or other third party material in this article are included in the article's Creative Commons licence, unless indicated otherwise in a credit line to the material. If material is not included in the article's Creative Commons licence and your intended use is not permitted by statutory regulation or exceeds the permitted use, you will need to obtain permission directly from the copyright holder. To view a copy of this licence, visit http://creativecommons.org/licenses/by/4.0/.

\section{References}

1. Siebenpfeiffer, W.: "Leichtbau-Technologien im Automobilbau," ATZ/MTZ-Fachbuch, 1, SpringerVieweg., (2014)

2. Thomason, J.L., Vlug, M.A.: Influence of fibre length and concentration on the properties of glass fibre-reinforced polypropylene: 1 . Tensile and flexural modulus, Composites Part A: Applied Science and Manufacturing 27(6), 477-484 (1996)

3. Thomason, J.L., Vlug, M.A.: Influence of fibre length and concentration on the properties of glass fibre-reinforced polypropylene: 4. Impact properties, Composites Part A: Applied Science and Manufacturing 28(3), 277-288 (1997)

4. Thomason, J.L., Vlug, M.A.: Schipper G, Krikor HGLT: Influence of fibre length and concentration on the properties of glass fibre-reinforced polypropylene: Part 3. Strength and strain at failure, Composites Part A: Applied Science and Manufacturing 27(11), 1075-1084 (1996)

5. Barkoula, N.-M., Karger-Kocsis, J.: Effects of fibre content and relative fibre-orientation on the solid particle erosion of GF/PP composites. Wear 252, 80-87 (2002)

6. Martinsen, K., Hu, S.J., Carlson, B.E.: Joining of dissimilar materials. CIRP annals -Manufacturing Technology 64, 696-699 (2015)

7. Mitschang, P., Velthuis, R., Rudolf, R.: Fügeverfahren für FKV. in Neitzel M., Mitschang P. Handbuch Verbundwerkstoffe. 2. Auflage, Carl Hanser, München-Wien 469-482, (2014)

8. Schürmann, H.: Klebeverbindungen. In: Konstruieren mit Faser-Kunststoff-Verbunden, Springer Verlang, Berlin-Heidelberg 569-604 (2005)

9. Brockmann, W.: Adhesive Bonding of Polypropylene. In Karger-Kocsis J. Polypropylene: An A-Z Reference, Kluwer, London 1-6 (1999)

10. Dawai, Z., Qi, Z., Xiaoguang, F., Shengdung, Z.: Review on Joining Process of Carbon Fiber Reinforced Polymer and Metal: Methods and Joining Process. Rare Metal Materials and Engineering 47(12), 3686-3696 (2018)

11. Parkers, P.N., Butler, R., Meyer, J., de Oliveria, A.: Static strength of metal-composite joints with penetrative reinforcement. Compos. Struct. 118, 250-256 (2014)

12. Ucsnik, S., Scheerer, M., Zaremba, S., Pahr, D.H.: Experimental investigation of a novel hybrid metal-composite joining technology. Compos. A 41, 369-374 (2010)

13. Kolesnikov, B., Herbeck, L., Fink, A.: Fortschrittliche Verbindungstechniken von Faserverbundstrukturen, Institut für Strukturmechanik des Deutschen Zentrums für Luft- und Raumfahrt e.V., (2004)

14. Sarantinos, N., Tsantzalis, S., Ucsnik, S., Kostopoulos, V.: Review of through the thickness reinforced composites in joints, Composite Structures 229 (2019)

15. Sarantinos, N., Kostopoulus, V., Di Vito, G., Campoli, G.: Shape optimization of single-pin reinforcement in metal-composite joints. International Journal of Structural Integrity 11, 381-394 (2019)

16. Eberl, L., Avila Gray, L., Zaremba, S., Drechsler, K.: The effect of fiber undulation on the strain field for pinned composite/titanium joints under tension, Composites: Part A, 103 148-160 (2017)

17. Hufenbach, A.W., Kupfer, R., Hornig, A.: Thermoactivated Pinning - a novel joining technique for thermoplastic composites. Solid State Phenom. 188, 176-181 (2012)

18. Hufenbach, A.W., Gottwald, R., Kupfer, R.:Bolted Joints with Molded Holes for Textile Reinforced Thermoplastic Composites, $18^{\mathrm{TH}}$ International Conference on Composite Materials (2018)

19. Plettke, R., Schaub, A., Gröschel, C., Scheitler, C., Vetter, M., Hentschel, O., Ranft, F., Merklein, M., Schmidt, M., Drummer, D.: A new process chain for joining sheet metal to fiber composite sheets. Key Eng. Mater. 611-612, 1468-1475 (2014)

20. Kraus, M., Frey, P., Kleffel, T., Drummer, D., Merklein, M.: Mechanical joining without auxiliary element by cold formed pins for multi-material-systems, AIP Conference Proceedings 2113 (2019)

21. Meyer, J., Johns, M.: Profile of interfacing projections, US-Patent, US 8,387,229 B2 (2013) 
22. German Institute for Standardization: ISO / ASTM DIS 52900:2018: Additive manufacturing - Gernerel principles - Terminology (2018)

23. Degarmo, E. Paul; Black, J T.M. Kohser, Ronald A.: Materials and Processes in Manufacturing (9th ed.), Wiley (2003)

24. Ryan, E.M., Sabin, T.J., Watts, J.F., Whiting, M.J.: The influence of build parameters and wire batch on porosity of wire arc additive manufactured aluminum alloy 2319. J. Mater. Process. Technol. 262, 577-584 (2018)

25. Cherry, J.A., Davies, H.M., Mehmood, S., Lavery, N.P., Brown, S.G.R., Sienz, J.: Investigation into the effect of process parameters on microstructural and physical properties of 316L stainless steel parts by selective laser melting. The International Journal of Additive Manufacturing Technology 76, 869-879 (2015)

26. Strano, G., Hao, L., Everson, R.M., Evans, K.E.: Surface roughness analysis, modelling and prediction in selective laser melting. J. Mater. Process. Technol. 213, 589-597 (2013)

27. Hufenbach, A.W., Adam, F., Helms, O., Kupfer, R.: Gestaltung von textilverbundgerechten Fügezonen mit warmgeformten Bolzenlöcher. Zeitschrift Kunststofftechnik 6, 256-269 (2010)

28. Saudi Basic Industries: Corporation:GPP 45-70 Tape, https:/www.frt.sabic.com/frt-sabic-content/uploads/ 2016/03/SABIC-0218-A4-Datasheet-GPP-45-70-TAPE-FINAL-2-MARCH-2018.pdf, last access: 02/06/2020

29. Verein Deutscher Ingenieure: "VDI 3405 - Additive Fertigungsverfahren - Grundlagen, Begriffe, Verfahrensbeschreibungen." (2007)

30. Ciurana, J., Hernandez, L., Delgado, J.: Energy density analysis on single tracks formed by selective laser melting with CoCrMo powder material. The International Journal of Additive Manufacturing Technology 68, 1103-1110 (2013)

31. German Institute for Standardization: DIN EN ISO 4288:1998-04-00, Geometrical Product Specifications (GPS) - Surface texture: Profile method - Rules and procedures for the assessment of surface texture (ISO 4288:1996); German version EN ISO 4288 (1997)

32. German Institute for Standardization: DIN EN 60584-1:2014-07-00; Thermocouples - Part 1: EMF specifications and tolerances (IEC 60584-1:2013); German version EN 60584-1 (2013)

33. Kniepkamp, M., Fischer, J., \& Abele, E.: Dimensional accuracy of small parts manufactured by micro selective laser melting, Proceedings of the 27th Annual International Solid Freeform Fabrication Symposium 2016, Austin(TX) 1530-1537 (2016)

34. Buchbinder, D., Meiners, W., Pirch, N., Wissenbach, K., Schrage, J.: Investigation on reducing distortion by preheating during manufacture of aluminum components using selective laser melting. Journal of laser applications 26 (2014)

35. Delgado, J., Ciurana, J., Rodríguez, C.A.: Influence of process parameters on part quality and mechanical properties for DMLS and SLM with iron-based materials: The International Journal of Additive Manufacturing Technology 60, 601-610 (2012)

Publisher's Note Springer Nature remains neutral with regard to jurisdictional claims in published maps and institutional affiliations. 